\title{
An Empirical Investigation of Passenger Wait Time Perceptions Using Hazard-Based Duration Models
}

loannis Psarros, Konstantinos Kepaptsoglou, and Matthew G. Karlaftis National Technical University of Athens

\begin{abstract}
Waiting time in bus stops heavily affects traveler attitude towards public transportation and therefore is an important element for consideration when planning and operating a bus system. Furthermore, what passengers perceive as waiting time is often quite different from their actual waiting time at a bus stop. In this context, we present an empirical investigation of actual and perceived waiting times at bus stops for the case of a large bus network, using hazard-based duration models. The analysis is based on a questionnaire survey undertaken at bus stops of the Athens, Greece, bus network. Results indicate that age, trip purpose, and trip time period seem to have an impact on that perception, with older individuals, work, and education trips being factors that increase perceived waiting time and lead to an overestimation of actual waiting, while perceived waiting time decreases during morning time periods.
\end{abstract}

\section{Introduction}

Transit is an important element of a city's transportation system; transit systems offer sustainable and equitable transportation services to all travelers at low cost. 
However, despite advantages of transit usage for societies, its share in ridership is often significantly lower compared to that of private vehicles, a fact usually attributed to the reduced performance and quality of services offered by transit systems. Bus systems are the most common among transit systems in cities worldwide (Vuchic 2004); however, these systems exhibit considerably lower attraction to passengers, which is mostly a result of problematic operations and their interaction with the rest of traffic. Indeed, operational characteristics such as low travel speeds, inadequate frequencies, and lack of punctuality and schedule reliability do have a negative effect in bus transit ridership.

Waiting times in bus stops are among those elements heavily affecting the attitude of passengers towards using bus transit, as well as their opinions on the quality of transit services. Riders are expected to wait at stops for buses to arrive, being exposed to adverse weather conditions, crowding, and a surrounding environment of poor quality, while being stressed by waiting anxiety. As a result, what passengers perceive that waiting time is often much larger compared to the actual waiting time imposed by bus operations, especially when no information is given to them on expected bus arrivals (Mishalani et al. 2006).

In that context, this paper provides an empirical investigation of actual and perceived waiting times at bus stops in the case of a large bus network with the use of duration models. The analysis is based on a survey undertaken at over 30 bus stops of the Athens bus network, which consists of over 300 lines and serves 1.3 million passengers on a daily basis. The remainder of the paper is structured as follows: the next section provides a brief background of past work on bus waiting times. Next, a description of the dataset and the methodological aspects of the paper are given. Empirical findings are then presented and discussed. The paper concludes with major insights drawn from the preceding analysis.

\section{Background}

The issue of waiting times at bus stops has been a topic of interest for researchers for at least three decades, with efforts concentrating both on the actual and perceived waiting times. Jolliffe and Hutchinson (1975) offered a behavioral explanation of the relationship between bus and passenger arrivals at bus stops and their impact on waiting times, considering random and not random passenger arrivals. Turnquist (1978) identified the effects of service frequency and reliability on waiting times, and Bowman and Turnquist (1981) developed a model based on pas- 
senger decision making for analyzing the sensitivity of waiting time against service frequency and reliability. Lam and Morral (1982) examined the impact of weather on waiting times, and Van Evert (1987) developed a relationship between service frequency and waiting time. Zahir et al. (2000) analyzed the bus system of Dhaka based upon field surveys and offered observations on actual passenger waiting times. Salek and Machemehl (1999) used experimental data from the city of Austin, Texas, and developed a model for predicting bus passenger waiting time, and Hall (2001) described a survey for collecting passenger waiting time information with the support of Automatic Vehicle Location systems for verification.

Perception of bus waiting time was investigated by Baldwin et al. (2004). Passengers were presented with the opportunity to pay for immediate service rather than wait. The study indicated that waiting times are overestimated by a factor of two when imposed by the transit system. Michalani et al. (2006) investigated passenger wait time perception on bus stops and attempted to quantify the relationship between perceived and actual wait time with the use of linear regression. Their results indicated an overestimation of waiting time by passengers compared to their actual waiting time. Currie and Csikos (2007) focused on the impacts of transit reliability on waiting times and drew interesting conclusions on their relationship. Another study on passenger perception of waiting time by Iseki and Taylor (2008) indicated that passengers mostly want short and predictable waits in a safe environment and do not give much notice to the attractiveness of bus infrastructures. Fan and Machemehl (2009) investigated different operating characteristics as potential predictors of passenger waiting time and concluded that a linear model which related waiting times to headways was the preferred case. They also reported differences between their model and the traditional random model for passenger waiting time estimation.

Overall, the review revealed past work focusing on either prediction of actual waiting time or the analysis of perceived waiting time. In that context, this research contributes to the existing literature by examining the relationship between actual and perceived travel time, based on data collected by a combination of observations and personal interviews and the use of appropriate statistical methods (hazardbased duration models) for analyzing the effect of various explanatory factors to the passenger perception of waiting time. 


\section{Dataset and Preliminary Statistical Analysis}

The dataset used is based on an extensive field survey, which combined observations of actual waiting times for passengers at bus stops and personal interviews on their perception of waiting time. Passengers arriving at bus stops were randomly selected and their arrival time was recorded by interviewers. Shortly after their arrival, passengers were asked by the interviewers about their perception of waiting time at the bus stop, along with other information, while the interview starting time was recorded. Then, when the passengers boarded a bus, a note of their total actual waiting time was made. This way, both the actual and perceived waiting times were collected for the time up to the initiation of the interview, as well as the overall actual waiting time. The survey took place at 30 bus stops in Athens area, from 8 A.M. to 8 P.M. Bus stops with both frequent and infrequent bus arrivals were selected as survey locations, and a total of over 1,000 passengers were interviewed. Collected data included actual passenger arriving and interview time, total actual waiting time, perceived time, gender, age and trip purpose, while the period of the day for each interview (morning, afternoon, evening) was also indicated.

Preliminary statistical analysis of the results revealed a relative balance between male and female passengers ( $47 \%$ versus $53 \%$ ), while most passengers were of age between 18 and 65 . Further, over 35 percent of the respondents were traveling to or from their place of work. Tables 1 and 2 summarize actual and perceived average waiting times for different time periods, gender and age groups, and trip purposes.

By inspecting Table 1 and 2 results, it can be seen that perceived waiting time is, in most cases, increased by at least 50 percent compared to the actual waiting time. Furthermore, older age groups and passengers traveling to work or for personal affairs tend to overestimate their waiting time, compared to other categories. The same applies to passengers interviewed in the morning period. A preliminary interpretation of these overestimations by specific passenger groups can be qualitatively attributed to factors such as limited patience by older passengers and work anxiety affecting passengers traveling to work or for personal affairs. However, a detailed, model-supported statistical analysis would reveal the actual effects of the aforementioned factors to the actual and perceived waiting times. 


\section{Table 1. Actual and Perceived Average Waiting Times for Different Time Periods}

\begin{tabular}{lccc}
\hline Time period & $\begin{array}{c}\text { Average Perceived } \\
\text { Waiting Time (min) }\end{array}$ & $\begin{array}{c}\text { Average Actual } \\
\text { Waiting Time (min) }\end{array}$ & $\begin{array}{c}\text { Ratio of Average } \\
\text { Perceived to Average } \\
\text { Actual Waiting Time }\end{array}$ \\
\hline Morning & 6.18 & 3.56 & 1.74 \\
Afternoon & 6.48 & 4.58 & 1.41 \\
Evening & 6.25 & 3.83 & 1.63 \\
\hline
\end{tabular}

Table 2. Actual and Perceived Average Waiting Times for Different Sex and Age Groups and Trip Purposes

\begin{tabular}{lccc}
\hline Group & $\begin{array}{c}\text { Average Perceived } \\
\text { Waiting Time (min) }\end{array}$ & $\begin{array}{c}\text { Average Actual } \\
\text { Waiting Time (min) }\end{array}$ & $\begin{array}{c}\text { Ratio of Average } \\
\text { Perceived to Average } \\
\text { Actual Waiting Time }\end{array}$ \\
\hline AGE GROUP & & & \\
$<18$ & 7.65 & 5.56 & 1.38 \\
$18-30$ & 5.76 & 4.06 & 1.42 \\
$31-45$ & 6.30 & 3.85 & 1.64 \\
$46-65$ & 7.21 & 4.19 & 1.72 \\
$>65$ & 6.81 & 3.84 & 1.77 \\
\hline GENDER & & & \\
Men & 6.22 & 3.87 & 1.61 \\
Women & 6.53 & 4.30 & 1.52 \\
\hline TRIP PURPOSE & & & 1.40 \\
Return Home & 6.60 & 4.72 & 1.53 \\
Work & 7.23 & 4.73 & 1.14 \\
Education & 8.80 & 7.73 & 1.47 \\
Personal & 8.08 & 5.49 & 1.27 \\
Entertainment & 6.58 & 5.17 & 1.35 \\
Shopping & 7.91 & 5.86 & 2.03 \\
Other & 9.29 & 4.57 & \\
\hline
\end{tabular}

\section{Model}

\section{Overview}

Duration data refer to time (or duration) until or between occurrence of events (Hensher and Mannering 1994). Such data are often encountered in transportation, with examples such as the duration between traffic accidents or vehicle purchases, waiting time in traffic queues, and so on (Hensher and Mannering 1994; 
Washington et al. 2003). Hazard-based models have been developed especially for describing duration data (Hensher and Mannering 1994). In detail, consider an episode as the time period until the occurrence of an event (or the time period between successive events); a hazard function expresses the probability that this episode starting at time $t$ is terminated within a time interval $(t, t+\Delta t)$ provided that the event has not occurred before the beginning of the interval. For example, in the particular case investigated in this paper, waiting time refers to the time period (episode) until a passenger boards a bus (event). As a result, the probability of boarding the bus after waiting for a duration $\Delta t$ is represented by the hazard function.

Hazard-based duration models have been exploited in a field of transportation for modeling the duration between traffic accidents, the time up to capacity restoration following a traffic incident, the duration of trip decision making activities, automobile ownership time etc. (Hensher and Mannering 1994; Washington et al. 2003). As noted by Hensher and Mannering (1994), duration models "focus on the probability of an end-of-duration occurrence, given that the duration has lasted to some specified time." This implies that the terminating event is assumed to be related to the duration of an episode. As such, the underlying advantage of duration models compared to other approaches) is the fact that they allow the occurrence of an event to be formulated in terms of conditional probabilities with respect to factors affecting the duration of its preceding episode and therefore offer a "tight link between theory and an empirical approach" (Hensher and Mannering 1994). Similarly, in the context of this paper, any answer to the question on perceived waiting time asked as part of the personal interviews (occurrence of the event) is related to those factors affecting the perception of waiting time. Therefore, we consider duration models to be more appropriate for the problem at hand compared to other approaches (e.g., regression).

\section{Theoretical Background}

Following Washington et al. (2003), let $T$ be a nonnegative random variable that represents ( $a$ ) the perceived waiting time (duration) and (b) the difference between the perceived and actual waiting times. The probability distribution of $T$ can be represented in a number of ways, of which the survival and hazard functions are the most useful. The survival function is defined as the probability that $T$ is of length at least $t$ (i.e. perceived waiting time or the difference between perceived and actual waiting time at least $t \mathrm{~min}$ ) and is given by (Washington et al. 2003):

$$
F(t)=P(T \geq T), 0<t<\infty
$$


The notation used here suggests that $F(t)$ is a monotone left continuous function with $F(0)=1$ and $\lim _{t \rightarrow \infty} F(t)=0$. The probability density function (p.d.f.) of $T$ is (Washington et al. 2003):

$$
f(t)=\lim _{\Delta \rightarrow 0^{+}} \frac{P(t \leq T<t+\Delta t)}{\Delta t}=\frac{-d F(t)}{d t}
$$

The hazard function specifies the instantaneous failure rate at $T=t$, conditional upon survival to time $t$, and can be defined as follows (Washington et al. 2003):

$$
\lambda(t)=\lim _{\Delta t 0^{+}} \frac{P(t \leq T<t+\Delta t \mid T \geq t)}{\Delta t}=\frac{f(t)}{F(t)}
$$

It is important to note that hazard functions are extremely useful in practice. They indicate the rate at which perceived waiting time increases after lasting for time $t$, and for this reason is more interesting than the survival or the c.d.f. functions. Also, from Eq. (3) it can be seen that $I(t)$ specifies the distribution of $T$ since,

$$
I(t)=\frac{-d \log F(t)}{d t}
$$

by integrating and setting $F(0)=1$

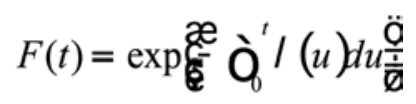

and the p.d.f. of $T$ becomes

$$
f(t)=I(t) \exp \underset{\xi}{\mathfrak{E}} \grave{Q}^{t} /(u) d u_{\dot{\bar{\ell}}}^{\ddot{c}}
$$

The literature suggests a wide variety of functional forms for the duration distributions such as the exponential, the Weibull, the Lognormal, the inverse normal, the Loglogistic, and others (Washington et al. 2010). Interestingly, these distributions display very different behaviors, and the selection of the functional form to be used will have important implications in the practical significance of the results.

\section{Variables}

Selected dependent variables are (a) the perceived waiting time by passengers and (b) the difference between the perceived and actual waiting times. Explanatory variables include sex, age, time period, travel purpose, and actual waiting time 
(when the dependent variable is the perceived waiting time). Both dependent and explanatory variables are shown in Table 3.

Table 3. Dependent and Explanatory Variables

\begin{tabular}{|c|c|c|}
\hline Variable Name & Description & Values \\
\hline \multicolumn{3}{|c|}{ Dependent Variables } \\
\hline LOGPER & Perceived wait time difference & Any \\
\hline LOGDIF & between perceived and actual wait times & Any \\
\hline \multicolumn{3}{|c|}{ Explanatory Variables } \\
\hline GENDER & Gender (male, female) & 0 for male, 1 for female \\
\hline AGE18 & Age & 1 for ages $<18,0$ otherwise \\
\hline AGE1830 & & 1 for ages $18-30,0$ otherwise \\
\hline AGE3045 & & 1 for ages $18-30,0$ otherwise \\
\hline AGE4565 & & 1 for ages $18-30,0$ otherwise \\
\hline AGE65 & & 1 for ages $<18,0$ otherwise \\
\hline HOME & Trip purpose & 1 for "return home," 0 otherwise \\
\hline WORK & & 1 for "work," 0 otherwise \\
\hline EDUC & & 1 for "education," 0 otherwise \\
\hline PERS & & 1 for "personal affairs," 0 otherwise \\
\hline ENTERT & & 1 for "entertainment," 0 otherwise \\
\hline SHOP & & 1 for "shopping," 0 otherwise \\
\hline TRAVEL & & 1 for "travel," 0 otherwise \\
\hline OTHER & & 1 for "Other," 0 otherwise \\
\hline QUE1 & Time period & 1 for $8: 00$ to $12: 00,0$ otherwise \\
\hline QUE2 & & 1 for $12: 00$ to $17: 00,0$ otherwise \\
\hline QUE3 & & 1 for $17: 00$ to $20: 00,0$ otherwise \\
\hline REALTIME & Actual wait time up to interview initiation & Any \\
\hline
\end{tabular}

In particular, five variables correspond to age groups of under 18, 18-30, 31-45, 46-65, and over 65; eight variables correspond to trip purposes (return home, work, education, shopping, entertainment, travel out of town, and other) ; and three variables are assigned to time periods (8:00-12:00, 12:00-17:00, 17:00-20:00).

\section{Empirical Findings}

Using previously described data and the duration model methodology, Tables 4 and 5 present model results for two duration distributions, Weibull and Loglogistic. 
Table 4. Model Results with Perceived Wait Time as Dependent Variable

\begin{tabular}{|c|c|c|c|c|c|c|}
\hline \multirow[b]{2}{*}{$\begin{array}{l}\text { Explanatory } \\
\text { Variables* }\end{array}$} & \multicolumn{3}{|c|}{ WEIBULL } & \multicolumn{3}{|c|}{ LOGLOGISTIC } \\
\hline & Coefficient & t-statistic & Hazard ratio** & Coefficient & t-statistic & $\begin{array}{l}\text { Hazard } \\
\text { ratio** }\end{array}$ \\
\hline CONSTANT & 0.687 & 40.19 & 1.988 & 0.691 & 28.27 & 1.996 \\
\hline AGE18 & & & & 0.066 & 2.40 & \\
\hline AGE3045 & 0.037 & 2.39 & 1.038 & & & 1.000 \\
\hline AGE4565 & 0.084 & 5.81 & 1.088 & 0.040 & 2.82 & 1.041 \\
\hline AGE65 & 0.077 & 4.12 & 1.080 & & & \\
\hline HOME & 0.175 & 8.49 & 1.191 & 0.082 & 2.85 & 1.085 \\
\hline WORK & 0.241 & 12.21 & 1.273 & 0.091 & 3.47 & 1.095 \\
\hline EDUC & 0.361 & 10.84 & 1.435 & 0.164 & 4.32 & 1.178 \\
\hline PERS & 0.265 & 12.61 & 1.303 & 0.135 & 4.94 & 1.145 \\
\hline ENTERT & 0.196 & 9.01 & 1.217 & 0.068 & 2.35 & 1.070 \\
\hline SHOP & 0.262 & 11.64 & 1.300 & 0.137 & 4.56 & 1.147 \\
\hline OTHER & 0.367 & 8.81 & 1.443 & 0.164 & 3.92 & 1.178 \\
\hline QUE1 & -0.041 & -2.18 & 0.960 & & & \\
\hline
\end{tabular}

*Non-significant variables for both distributions are omitted.

**Proportional change in hazard given a unit change in explanatory variable (all other variables assumed fixed).

Table 5. Model Results with Difference Between Perceived and Actual Wait Times as Dependent Variable

\begin{tabular}{|c|c|c|c|c|c|c|}
\hline \multirow[b]{2}{*}{$\begin{array}{l}\text { Explanatory } \\
\text { Variables* }\end{array}$} & \multicolumn{3}{|c|}{ WEIBULL } & \multicolumn{3}{|c|}{ LOGLOGISTIC } \\
\hline & Coefficient & t-statistic & Hazard ratio** & Coefficient & t-statistic & $\begin{array}{l}\text { Hazard } \\
\text { ratio** }\end{array}$ \\
\hline CONSTANT & 0.648 & 44.25 & 1.912 & 0.491 & 30.15 & 1.634 \\
\hline GENDER & 0.000 & 4.82 & 1.000 & 0.000 & 4.43 & 1.000 \\
\hline AGE1830 & -0.040 & -3.21 & 0.961 & -0.030 & -2.17 & 0.970 \\
\hline AGE3045 & -0.051 & -3.22 & 0.950 & -0.035 & -2.11 & 0.966 \\
\hline HOME & 0.127 & 6.20 & 1.135 & 0.146 & 7.30 & 1.157 \\
\hline WORK & 0.146 & 10.03 & 1.157 & 0.152 & 9.12 & 1.164 \\
\hline EDUC & 0.285 & 9.48 & 1.330 & 0.172 & 4.60 & 1.188 \\
\hline PERS & 0.150 & 7.55 & 1.162 & 0.162 & 8.20 & 1.176 \\
\hline ENTERT & 0.183 & 11.66 & 1.201 & 0.159 & 7.37 & 1.172 \\
\hline SHOP & 0.238 & 13.21 & 1.269 & 0.187 & 7.40 & 1.206 \\
\hline OTHER & 0.185 & 3.62 & 1.203 & 0.184 & 4.21 & 1.202 \\
\hline QUE1 & -0.060 & -3.92 & 0.942 & & & \\
\hline QUE2 & & & & 0.054 & 3.35 & 1.055 \\
\hline QUE3 & -0.030 & -2.47 & 0.970 & 0.043 & 2.47 & 1.044 \\
\hline REALTIME & 0.010 & 4.38 & 1.010 & 0.000 & 3.42 & 1.000 \\
\hline
\end{tabular}

${ }^{*}$ Non-significant variables for both distributions are omitted.

**Proportional change in hazard given a unit change in explanatory variable (all other variables assumed fixed). 
It should be noted here that the hazard functions for the Loglogistic and Weibull distributions are given by $I p(I t)^{p-1} / 1+(I t)^{p}, I p(I t)^{p-1}$, respectively; for the same distributions, the survival functions are $1 / 1+(I t)^{p}, \mathrm{e}^{-(I t)^{p}}$.

It is evident from Tables 4 and 5 that the different functional forms of the Weibull and Lognormal distribution lead to very different qualitative conclusions. For example, as can be seen from Figure 1, the Weibull distribution is monotonically increasing, indicating a continuously increasing hazard rate over time, while the Loglogistic suggests an initial increase and then a decrease in the hazard rate (Washington et al. 2010).

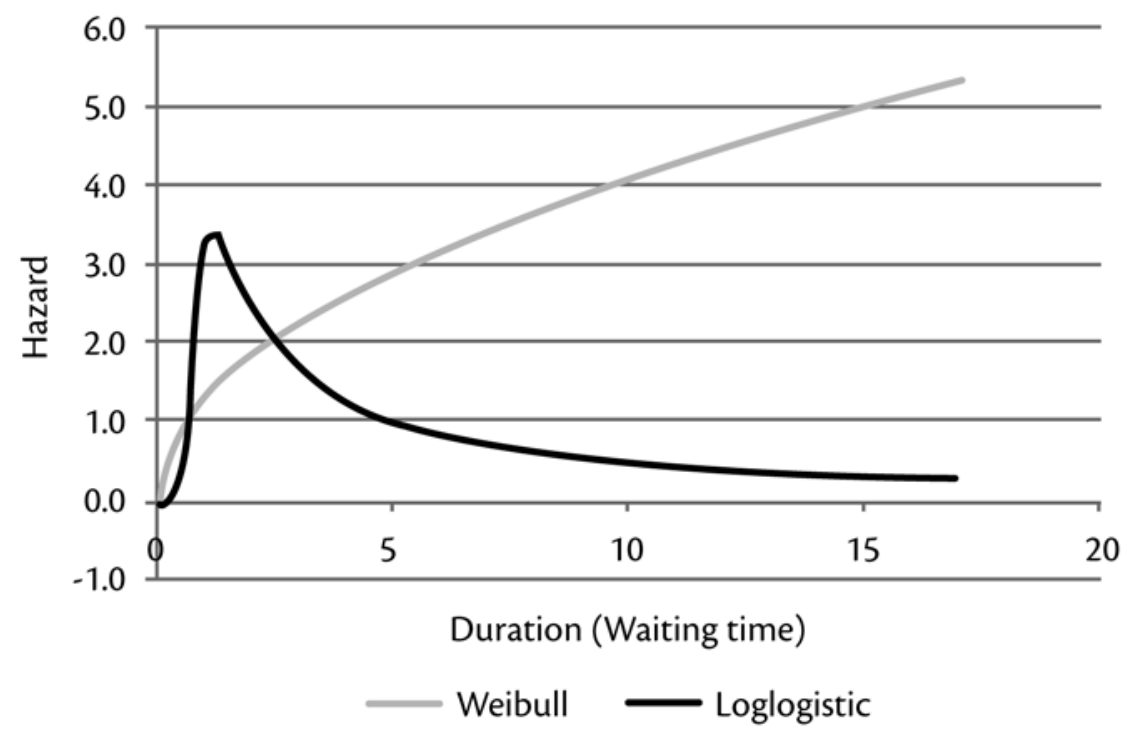

Figure 1. Weibull and Loglogistic hazard functions

The obvious question then becomes, how can the "best" fitting distribution be selected? Besides theoretical arguments, the statistical answer to this question is not straightforward. In general, for a model to be appropriate for the data, the graph for each of the functional forms needs to be a straight line through the origin (for the exponential model, for example, it is the graph of the log of the survival versus $t$ ). However, it is interesting to note that the Weibull and Loglogistic functional forms are all nested within the generalized gamma model, making it a simple matter to evaluate them with the likelihood ratio test (Lee and Wang 2003; Cleeves et al. 2008). Final likelihood values indicate that the Weibull distribution is more 
suitable for describing both the perceived waiting time and the difference between the perceived and the actual waiting time.

With respect to the interpretation of results, Table 4 presents those factors affecting perceived waiting time. According to Table 4 results (for the Weibull distribution), perceived waiting time increases for ages of over 18 years (positive coefficients of $0.037,0.084$ and 0.077 , respectively), while a larger effect on the length of perceived waiting time is observed for ages over 45 years. Indeed, for ages between 45 and 65 , a hazard ratio of 1.088 implies that for this age category, perceived waiting time increases by 8.8 percent. All trip purposes appear to have a strong positive effect on the length of perceived waiting time. In particular, trip purposes directly related to certain activities (such as trips made for work, education, and personal affairs) tend to have a stronger effect on increased perceived waiting times. Trips to work, for example, lead to an increase in perceived waiting time of 27.3 percen, $t$ while the corresponding percentages for education and personal affairs are 43.5 percent and 30.3 percent, respectively. Interestingly, shopping activities have a similar effect on perceived waiting time by 30 percent. On the other hand "return home" and entertainment seem to have a lower (yet positive) impact on the length of perceived travel times compared to other purposes (hazard ratios of 1.191 and 1.217). Finally, the morning time period seems to have a negative effect on perceived waiting times (with a coefficient of -0.041), a fact that can be attributed to more frequent bus arrivals at the bus stops. In particular, the hazard ratio value of 0.96 implies that perceived waiting time is reduced by 4 percent during morning periods.

Table 5 results refer to the difference between perceived and actual waiting times and practically indicate the degree of waiting time overestimation by travelers. Results (again for the Weibull distribution) show that younger passengers (up to 30 years of age) tend to have a better perception of waiting times (coefficients of -0.040 and -0.051 ). Hazard ratios indicate that for these categories, the difference between perceived and actual waiting time is 4 percent- 5 percent. Trip purpose seems to positively affect overestimation of travel time perception, particularly for work-related trips, shopping, and entertainment. For example, for work trips, passengers tend to overestimate their waiting time by 15.7 percent, while for education trips this percentage rises to 33 percent. We also find that at morning and afternoon periods, there is a better perception of waiting times. Overall, age, trip purpose and the morning and afternoon periods seem to affect perception of waiting time in bus stops. 


\section{Conclusions}

Waiting time at bus stops is evidently one of those key factors affecting the attractiveness and performance of bus systems. Nevertheless, its perceived value practically dictates rider discomfort and preference towards bus services. In this context, this paper focused on investigating the effects of various factors on perceived waiting time using appropriate hazard-based duration models. The use of duration models was dictated by the nature of the problem at hand, which fits the underlying theoretical rationale behind using these models. Results indicated that age, trip purpose, and trip time period seem to have an impact on that perception, with older individuals, work trips, and education trips being factors that increase perceived waiting time and lead to an overestimation of actual waiting, while perceived waiting time decreases during morning time periods.

\section{References}

Baldwin Hess, D., J. Brown, and D. Shoup. 2004. Waiting for the bus. Journal of Public Transportation 7(4): 67-84.

Bowman, L.A, and M. A. Turnquist. 1981. Service frequency, schedule reliability and passenger wait times at transit stops. Transportation Research Part A: Policy and Practice 15A(6): 465-471.

Cleeves, M., R. Guttierez, W. Gould, and Y. Marchenko. 2008. An Introduction to Survival Analysis Using Stata, 2nd Ed. Stata Press, College Station, TX.

Currie, G., and D. R. Csikos. 2007. The impacts of transit reliability on wait time: Insights from automated fare collection system data. Proceedings of the 86th Transportation Research Board Annual Meeting, Washington, D.C., USA.

Evert, V. 1987. Relatie tussen frequentie en werkelijke wachttijd. Verkeerskunde 38(10): 430-433.

Fan, W., and R. Machemehl. 2009. Do transit users just wait for buses or wait with strategies? Some numerical results that transit planners should see. Transportation Research Record 2111: 169-176

Hall, R. W. 2001. Passenger waiting time and information acquisition using automatic vehicle location for verification. Transportation Planning and Technology 24(3): 249-269. 
Hensher, D. A., and F. L. Mannering.1994. Hazard-based duration models and their application to transport analysis. Transport Reviews 14(1): 63-82.

Iseki, H., and B. Taylor. 2008. Style versus service? An analysis of user perceptions of transit stops and stations in Los Angeles. Proceedings of the 87th Transportation Research Board Annual Meeting, Washington, D.C., USA.

Jollife, J.K., and T. P. Hutchinson. 1975. A behavioural explanation of the association between bus and passenger arrivals at a bus stop. Transportation Science 9(3): 249-282

Lam, W., and J. Morrall. 1982. Bus passenger walking distances and waiting times: A summer-winter comparison. Traffic Quarterly 36(3): 407-421.

Lee, E. T., and J. W. Wang. 2003. Statistical Methods for Survival Data Analysis 3rd Edition. Wiley and Sons, Hoboken, NJ.

Mishalani, R., M. McCord, and J. Wirtz. 2006. Passenger wait time perceptions at bus stops: Empirical results and impact on evaluating real-time bus arrival information. Journal of Public Transportation 9(2): 89-106.

Salek, M-D, and R. Machemehl. 1999. Characterizing bus transit passenger wait times. Report SWUTC/99/167211-1, University of Texas at Austin and Southwest Region University Transportation Center, USA.

Turnquist, M. A. 1978. A model for investigating the effects of service frequency and reliability on bus passenger waiting times. Transportation Research Record 663: 70-73.

Vuchic, V. 2004. Urban Transit: Operations, Planning and Economics. John Wiley and Sons Inc. Hoboken, NJ, USA.

Washington, S., M. Karlaftis, and F. Mannering. 2003. Statistical and Econometric Methods for Transportation Data Analysis. Chapman \& Hall/CRC Press, Boca Raton, FL, USA.

Washington, S., M. Karlaftis, and F. Mannering. 2010. Statistical and Econometric Methods for Transportation Data Analysis - 2nd Edition. Chapman \& Hall/CRC Press, Boca Raton, FL, USA.

Zahir, U., H. Matsui, and M. Fujita. 2000. Investigation of the effects of bus and passenger arrival patterns and service frequency on passenger waiting time and transit performance of Dhaka metropolitan area. Proceedings of the Sixth 
International Conference on Urban Transport and the Environment for the 21st Century, Cambridge University, Cambridge, UK: 55-64.

\section{About the Authors}

loANNIS PsarRos (psmmpg@yahoo.gr) is a master's student at the School of Civil Engineering of the National Technical University of Athens. His research interests include transportation planning and design of public transportation systems.

Konstantinos Kepaptsoglou (kkepap@central.ntua.gr) is a post-doctoral researcher at NTUA. He holds a Civil Engineering diploma from NTUA, a master's degree from Purdue University, and a PhD from NTUA. His research interests include public transportation, transportation planning, railway planning and design, and operations research.

MATthew G. KARLAfTIS (mgk@central.ntua.gr) is an Associate Professor of the School of Civil Engineering of NTUA. His educational background includes B.Sc. and M.Sc. degrees from the University of Miami and a Ph.D. from Purdue University. His research has focused on a variety of aspects related to transportation planning, traffic engineering, operations research, and statistics. He is a co-author of over 70 publications in peer reviewed journals and an area editor of ASCE's Journal of Transportation Engineering. 